IOSR Journal of Pharmacy

ISSN: 2250-3013, www.iosrphr.org

||| Volume 2 Issue 5 ||| Sep-Oct. 2012 ||| PP.39-45

\title{
An isolated chicken ileum: Alternative to laboratory animals for isolated tissue experimentation.
}

\author{
V.R.Undale ${ }^{1}$,P.N.Jagtap ${ }^{1}$,A.V.Yadav ${ }^{1}$, S.K.Sangamnerkar ${ }^{1}$, \\ C.D.Upasani ${ }^{2}$, A.V.Bhosale ${ }^{1}$. \\ ${ }^{1}$ Department of Pharmacology, PDEA's SGRS College of Pharmacy Saswad, Pune- 412301. \\ ${ }^{2}$ Department of Pharmacology, SNJB's Shriman Sureshdada Jain College of Pharmacy, \\ Chandwad, Nashik, Maharashtra, India.423101
}

\begin{abstract}
Animal testing means the use of non-human animals in experiments. About 50 to 100 million vertebrates including rodents and non rodents are used for the purpose of such experiments in education and research. The non judicious use of these animals has affected the eco system and therefore many countries and scientists are looking for the alternatives for animal testing. The two major alternatives to in vivo animal testing are in vitro cell culture technique and in silico computer simulation. Still the alternative to animal testing needs to be developed. The present study was undertaken to justify the use of small intestine of chicken for isolated tissue experimentation which is a waste organ easily available from slaughter houses. The previous studies on chicken small intestine revealed the presence of tachykinin, histaminic, and motilin receptors. In the present study ileum portion of small intestine was used in tissue preparation. The contractile responses of variable doses of Acetylcholine solution were recorded on kymograph paper. The experiments were repeated to check the reproducibility, sensitivity and accuracy. The various parameters as tissue length, load/tension, magnification value, and physiological salt solution were studied to optimize the tissue experimentation conditions. The study showed that the chicken ileum may be one of the best, cheapest and easily available non mammalian tissues for experimentation on isolated organs and amongst various solutions Ringer Lock is the most suitable physiological solution.
\end{abstract}

Keywords-acetylcholine, PSS, chick ileum

\section{INTRODUCTION}

Animal testing which is also known as in vivo testing means the use of non-human animals in experiments. About 50 to 100 million vertebrates are used worldwide for the purpose of education and research. The research is conducted inside universities, medical schools, pharmaceutical companies, and includes pure research such as genetics, developmental biology, behavioral studies, as well as applied research such as biomedical research, xeno-transplantation, drug testing and toxicology tests, including cosmetics testing. Sources of laboratory animals vary from countries and species; while most animals are purpose-bred, others may be caught in the wild or supplied by dealers. The rodents like mice, rats, rabbit's guinea pigs, hamsters and non human primates are widely used for experimentation. The non judicious use of these animals has affected the eco system and therefore many countries and scientists are looking for the alternatives for animal testing. The two major alternatives to in vivo animal testing are in vitro cell culture technique and in silico computer simulation. But still the alternative to animal testing needs to be developed. The present study was undertaken to exploit the small intestine of chicken for isolated tissue experimentation which is a waste product easily available from slaughter houses. The previous studies on chicken small intestine revealed the presence of tachykinin, histaminic, motile receptors ${ }^{1}$. In the present study, ileum portion of chick small intestine was used and various parameters were studied to optimize the conditions as physiological salt solution, tissue length, magnification value and load/ tension. The contractile response of variable doses of Acetylcholine solution (Stalk solution: $1 \mathrm{mg} / \mathrm{ml}$ ) were recorded with the help of frontal writing lever. The experiments were repeated for number of times to check the reproducibility, sensitivity and accuracy. The composition of Physiological salt solution was modified so as to find out most suitable Physiological salt solution that can be used. From the experiments carried out, it was found that chicken ileum may be one of the best, cheapest and easily available non mammalian tissues for experimentation on isolated organs. 
An isolated chicken ileum: alternative to laboratory animals for isolated tissue experimentation.

\subsection{Alternatives to Animal Experimentation}

Because of the growing concern on the use of animals in biochemical research several of the industrialized countries of Europe and North America have passed legislation to prevent or curtailment of animal experimentation. These include experiments with tissues and body fluids of normal animals and human, use of micro-organisms, primary cell culture, and cell lines. Use of models and computer programs are other alternatives though provide valuable information, they are expensive and at times do not represent the exact response or affect that one would get using intact animals ${ }^{2}$.

The laboratory animals have to be sacrificed just for a piece of tissue. However, chick ileum is a tissue that is available easily, and animals need not be killed additionally for experimental purpose. The advantages of using chick ileum preparation are that it is economical, very easy to mount in organ bath, gives good response, without sacrificing the experimental animals ${ }^{2}$.

\subsection{Biological Standardization (Bioassays) ${ }^{2}$}

Biological standardization or bioassays are procedures by which the potency or the nature of the substance is estimated by studying its effect on living matter. Bioassay procedure are generally employed

1. When a chemical assay for the substance is not available or the substance gets inactivated by interacting with chemicals as the case with hormones.

2. When the quantity of the sample is too small. In such situation a matching type of bioassay is conveniently done to compare the biological response with the standard drug.

3. To estimate the concentration of active principles present in the tissue extract, the endogenous mediators like acetylcholine, 5HT, prostaglandins.

4. To measure the pharmacological activity of new or chemically unidentified substance.

5. To measure drug toxicity.

6. When the bioassay is more sensitive than the chemical assay

\section{MATERIAL AND METHODS}

The present study was undertaken using graded type of bioassay.

\subsection{Procurement of Chick ileum}

Chick ileum was procured from the local market in Saswad, Dist Pune.

\subsection{Chemicals:}

All other chemicals used are of laboratory grade.

Sodium Chloride, Potassium Chloride, Calcium Chloride, Magnesium Chloride, Magnesium Sulphate, Sodium bicarbonate, Sodium hydrogen phosphate, Potassium hydrogen phosphate and distilled water. Acetylcholine stock solution $(1 \mathrm{mg} / \mathrm{ml})$

Table 1 Preparation of physiological salt solution (PSS):

\begin{tabular}{|l|l|l|l|l|l|}
\hline Compound & Frog Ringer & Ringer Locke & De Jalon & Tyrode & Krebs \\
\hline $\mathrm{Nacl}$ & 6 & 9.0 & 9 & 8.0 & 6.9 \\
\hline $\mathrm{Kcl}$ & 0.14 & 0.42 & 0.42 & 0.2 & 0.35 \\
\hline $\mathrm{CaCl}$ & 0.12 & 0.24 & 0.06 & 0.2 & 0.28 \\
\hline $\mathrm{MgCl}_{2}$ & - & - & - & 0.10 & - \\
\hline $\mathrm{MgSo}_{4}$ & - & - & - & - & 1.28 \\
\hline $\mathrm{NaHco}_{3}$ & 0.2 & 0.5 & 0.5 & 1.0 & 2.1 \\
\hline $\mathrm{NaH}_{2} \mathrm{Po}_{4}$ & - & - & - & 0.05 & - \\
\hline $\mathrm{KH}_{2} \mathrm{Po}_{4}$ & - & - & - & - & 0.16 \\
\hline $\mathrm{Glucose}$ & 2 & 1.0 & 0.5 & 1 or 2 & 1 or 2 \\
\hline
\end{tabular}

All values are in $\mathrm{g} / \mathrm{l}$. Weighed accurate quantity of the ingredients and dissolved in one liter distilled water. The physiological solution prepared should be clear, and if turbid it is advised to prepare fresh solution before the start of the experiment.

\subsection{METHOD ${ }^{2}$ :}

1. Fresh entire gastrointestinal tract of healthy cock was obtained from a slaughter house in Saswad.

2. The caecum was lifted forwards and the ileocaecal junction was identified.

3. A few centimeters of the ileal portion was cut and removed and immediately placed it in the watch glass containing physiological salt solution. The mesentery and adhering tissues were removed with gentle care. Utmost care was taken to avoid any damage to the gut muscle. The ileum was cut into small segments of 2$3 \mathrm{~cm}$ long. 
An isolated chicken ileum: alternative to laboratory animals for isolated tissue experimentation.

4. To one piece of ileum the thread was tied to top and bottom ends without closing the ileum, and mounted the tissue in the organ bath containing PSS maintained at $32-35^{\circ} \mathrm{C}$ and bubbled with air. The magnification from 5-7 folds and bath volume of about $25 \mathrm{ml}$ was maintained, and the tissue was allowed to equilibrate for 30 min before adding Acetylcholine to the organ bath.

5. The Acetylcholine induces the contraction in the ileal smooth muscles which were recorded on Kymograph by using frontal writing lever. Contact time of $30 \mathrm{sec}$, and 5 min time cycle was kept for proper recording of the responses.

6. The CRC was recorded till ceiling effect to Acetylcholine was obtained.

7. Various parameters were changed and responses were taken as magnification value $3 \& 5$, load/tension 0.5 , $1.0 \& 1.5 \mathrm{gm}$ and tissue length $1.5,2.0 \mathrm{~cm}$.

8. All physiological salt solution was tried and responses were taken.

9. Height of response was measured.

\section{RESULTS}

From the experiments, it was found that the chick ileum was giving good responses in following optimized conditions:

$\checkmark \quad$ Physiological salt solution= Ringer lock (Fig.1,Graph 1)

$\checkmark$ Load/tension $\quad=1.5 \mathrm{gm}$ (Fig.2, Graph 2)

$\checkmark$ Tissue length $\quad=2.0 \mathrm{~cm}$ (Fig. 3, Graph 3)

$\checkmark$ Magnification value $=3.0$

With magnification value more than 3.0, responses were not proper. Also for the tension 1.0 gm was tried (result not shown), responses were not proper. Tissue length less than $1.5 \mathrm{~cm}$ was not showing satisfactory results. So the above conditions were optimized for the experiments with the chick ileum. To confirm the optimized conditions, Concentration response curve of Acetylcholine and Histamine was taken with the same conditions (Fig. 4 and Fig. 5).

\section{FIGURES AND TABLES}

Figure 1: Concentration response curves of Acetylcholine $(1 \mathrm{mg} / \mathrm{ml})$ with various physiological salt solutions. (A) Frog Ringer solution (B) Ringer Lock solution (C) De Jalon Solution (D) Tyrode solution (E) Kreb's solution.

Figure 2: Comparison for responses of acetylcholine with various physiological salt solutions.

Figure 3: Concentration response curves of Acetylcholine $(1 \mathrm{mg} / \mathrm{ml})$ with different load. (A) Load $0.5 \mathrm{gm}$ (B) Load 1.5gm

Figure 4: Comparison for responses of acetylcholine with different load applied.

Figure 5: Concentration response curves of Acetylcholine $(1 \mathrm{mg} / \mathrm{ml})$ with different tissue length. (A) Tissue length $1.5 \mathrm{~cm}(B)$ Tissue length $2.0 \mathrm{~cm}$

Figure 6: Comparison for responses of acetylcholine with different tissue length used.

Figure 7: Concentration response curve for acetylcholine with optimized conditions using isolated chick ileum tissue.

Figure 8: Concentration response curve for Histamine with optimized conditions using isolated chick ileum tissue.

Figure 1:

(A)

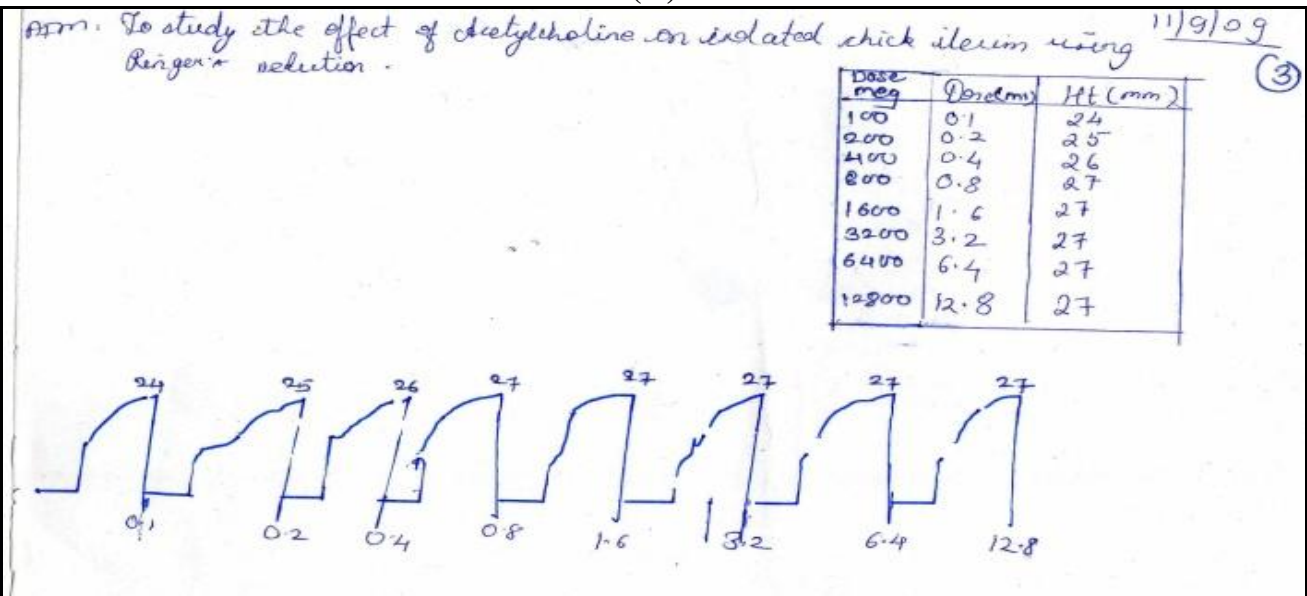


(B)

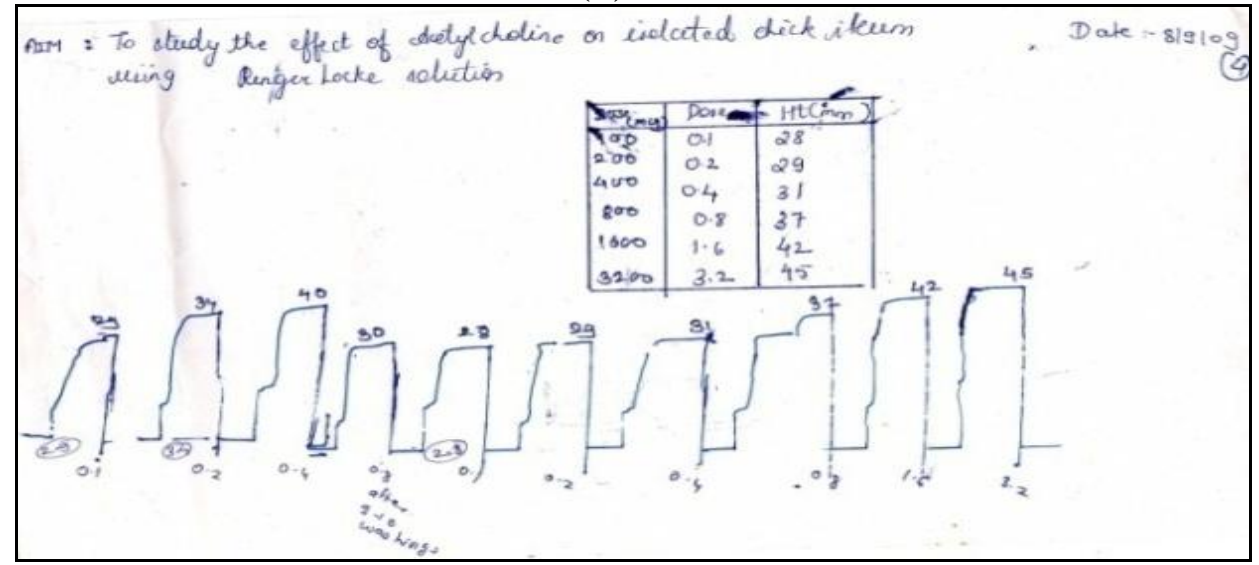

(C)

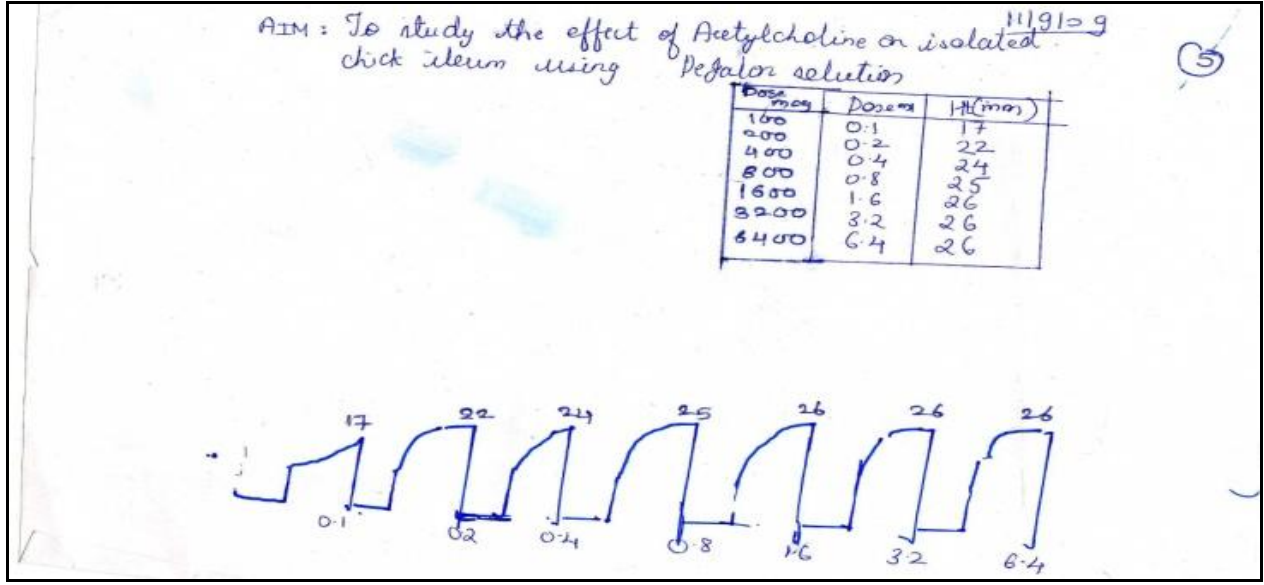

(D)

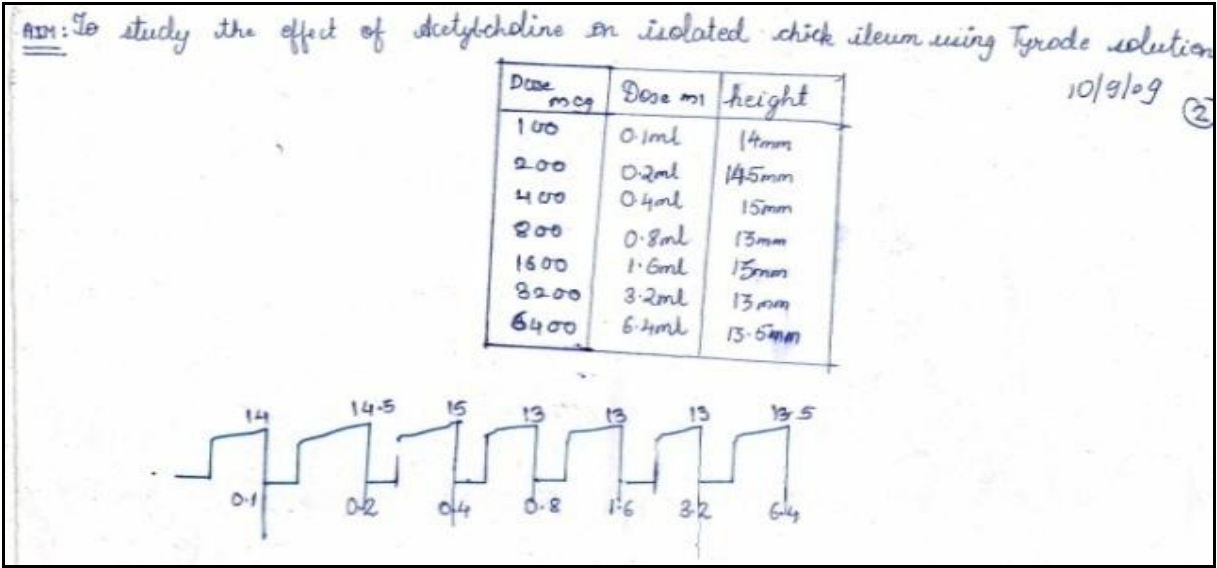

(E)

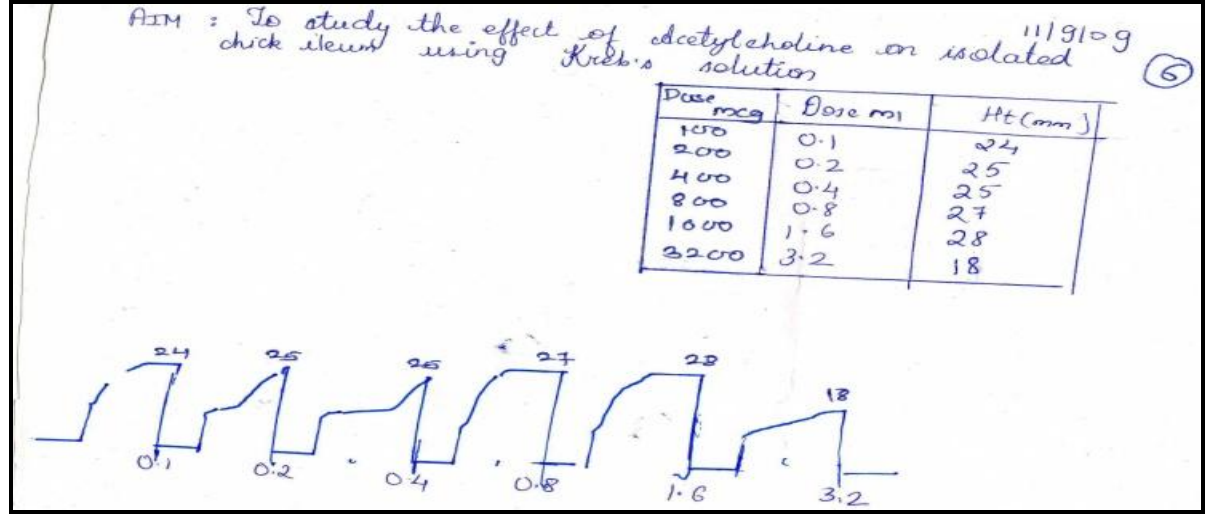


Figure 2

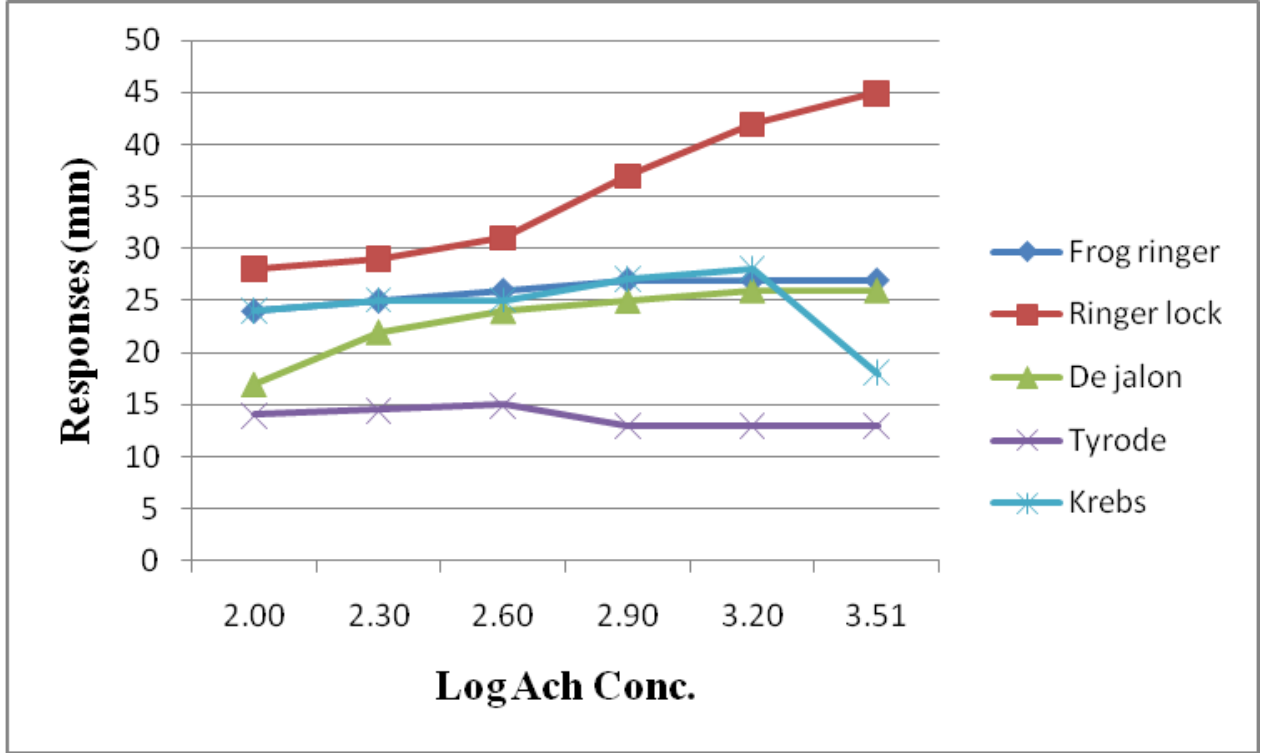

Figure 3:
(A) Load 0.5 gm

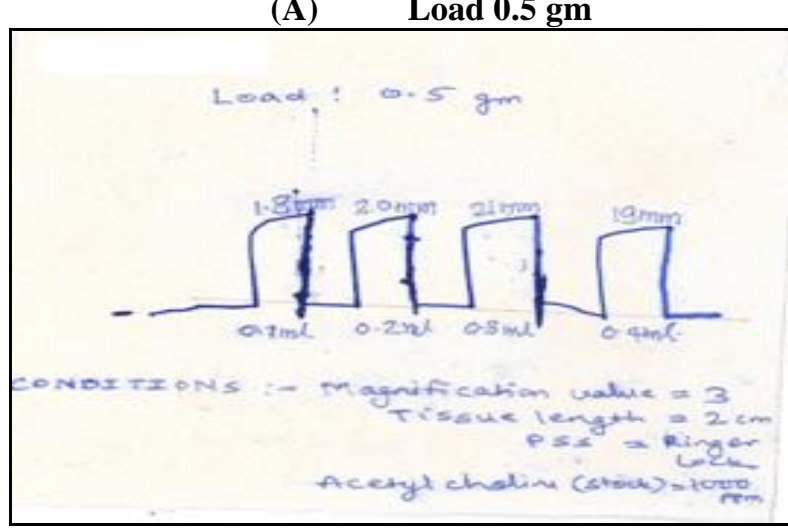

(B) Load 1.5 gm

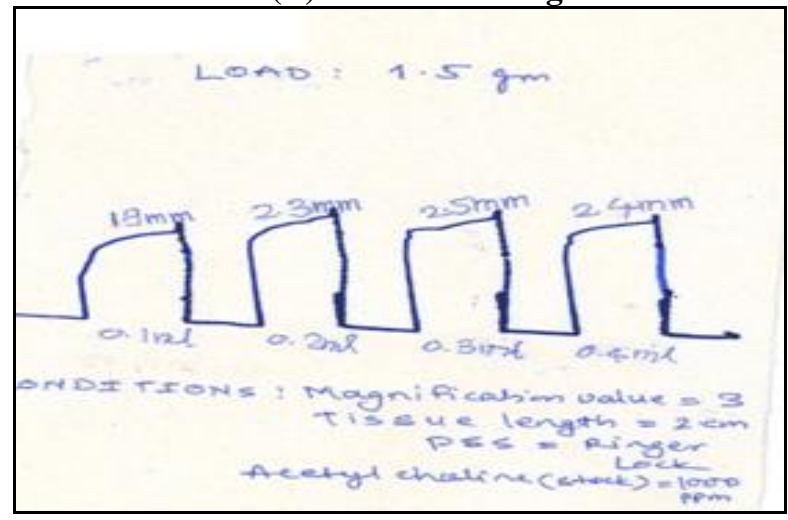

Figure 4:

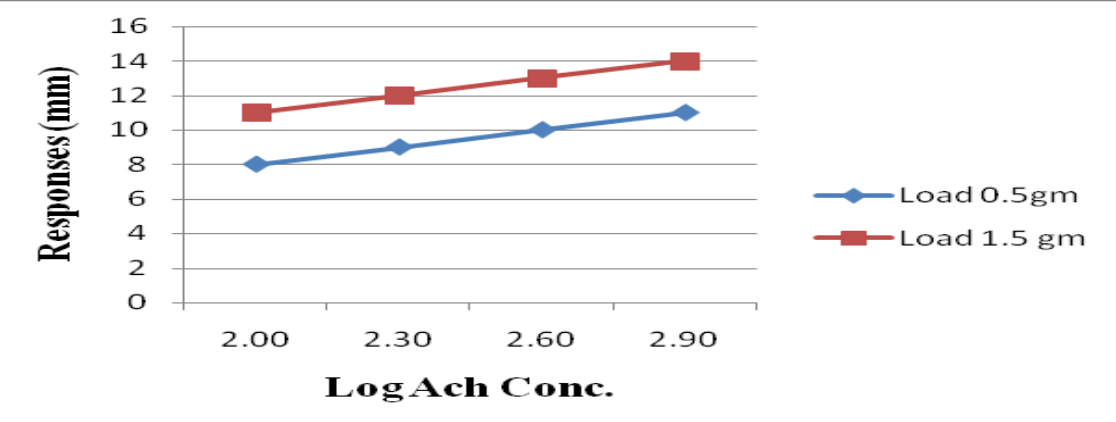


Figure 5:

(A)Tissue length $1.5 \mathrm{~cm}$

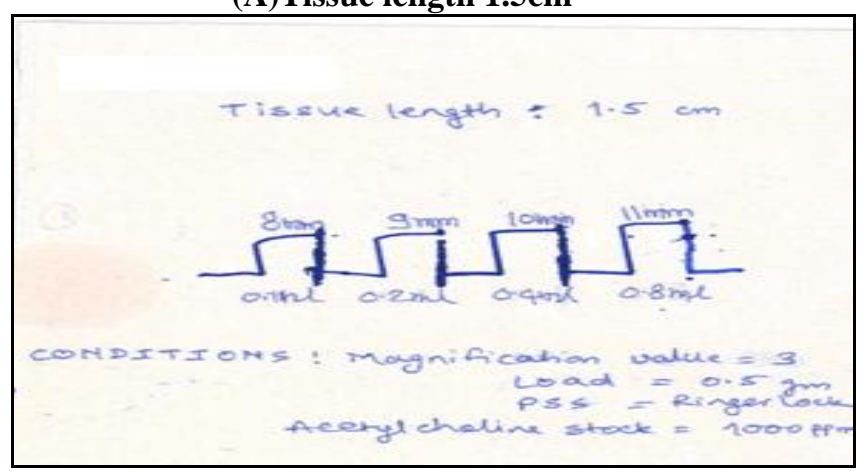

(B)Tissue length 2.0cm

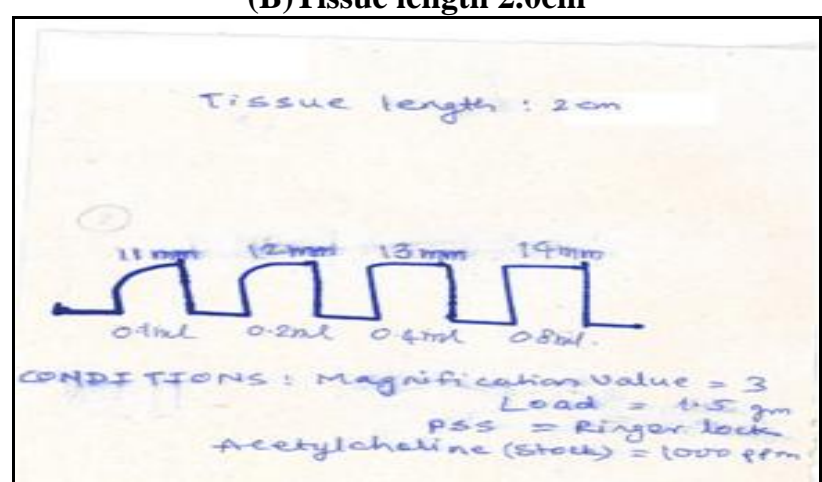

Figure 6:

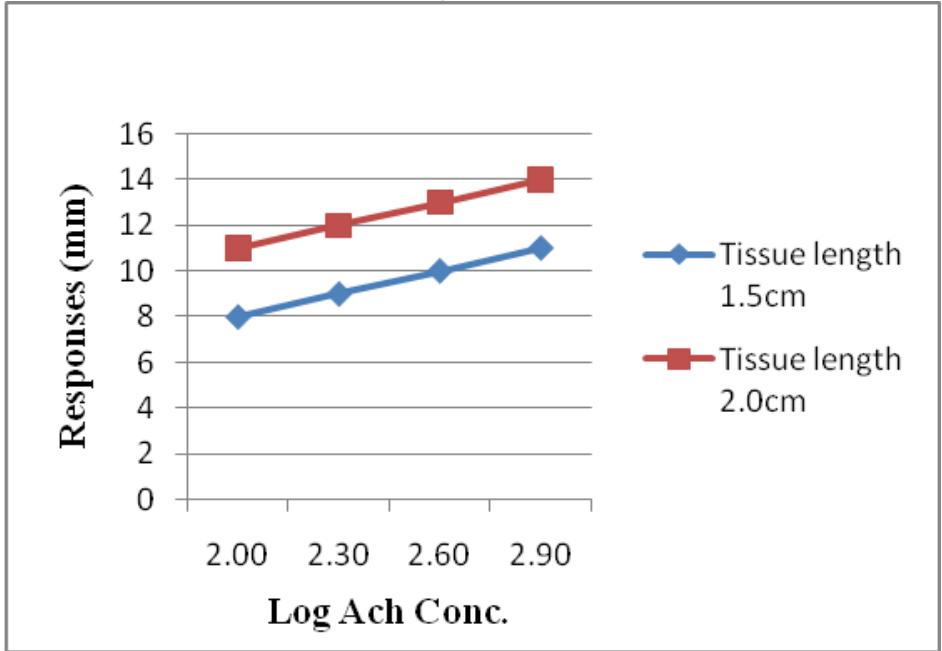

Figure 7:

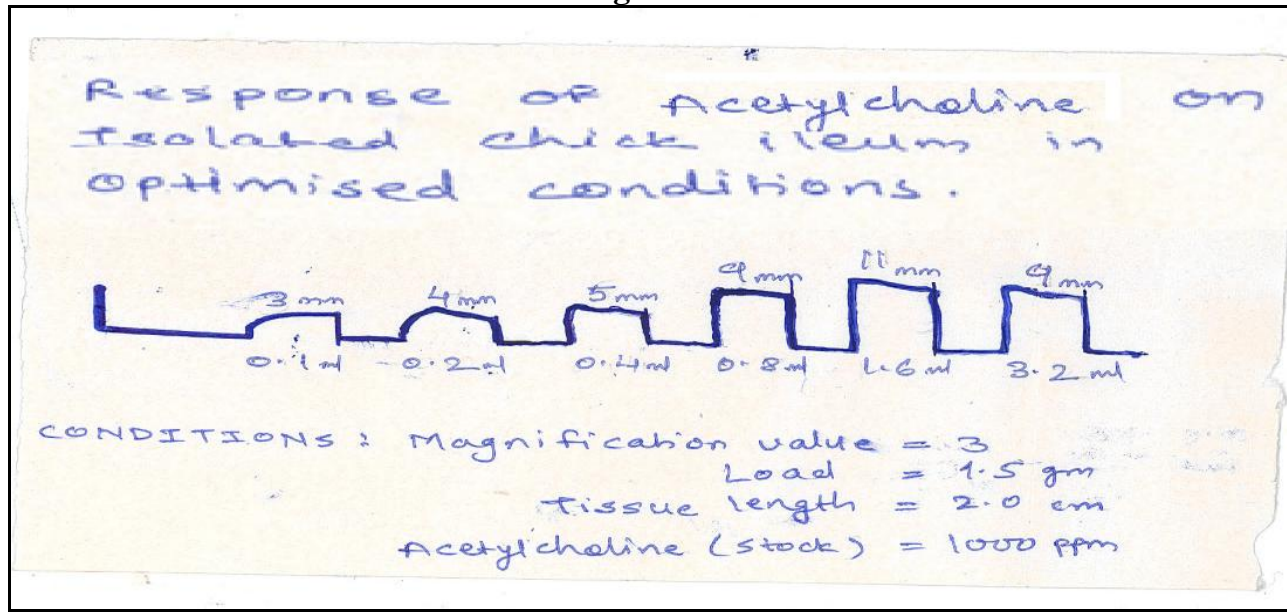


Figure 8:

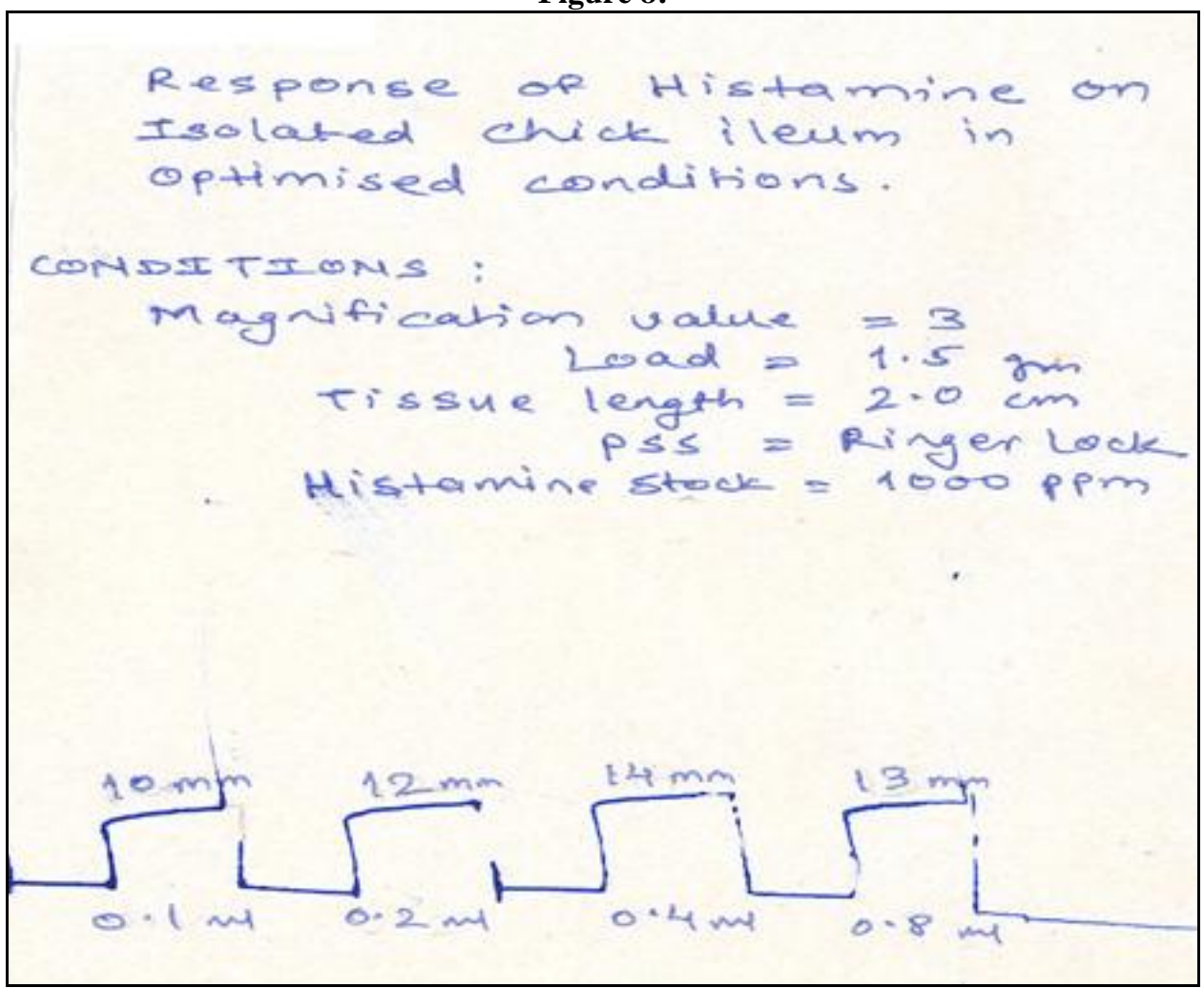

\section{DISCUSSION}

In preclinical studies rat/ guinea pig ileum is widely used isolated tissue for various laboratory experimentations due to presence of various receptors as muscarinic, serotonin, histaminic, GABAnergic, and adrenoreceptors ${ }^{3}$. As cock ileum contains tachykinin, histaminic, motile receptors, isolated ileum is suitable for carrying out various experiments like determination of $\mathrm{pA}_{2}$ value, three point/ four point bioassay, demonstration of potentiating effect of acetylcholine by neostigmine, comparison of activities of different agonists like acetylcholine and barium chloride ${ }^{4}$.

For its use in educational purpose and new drug discovery process, optimization of experimental conditions would help. In the present investigation, conditions such as tissue length, load/tension to be applied, magnification value, PSS to be used were optimized. It was found that with the optimized conditions as tissue length $=2.0 \mathrm{~cm}$, load $/$ tension $=1.5 \mathrm{gm}$, magnification value $=3.0$ and Ringer lock as physiological salt solution CRC of Acetylcholine and Histamine recorded correlates with the CRC of Acetylcholine and Histamine recorded using isolated rat ileum.

\section{CONCLUSION}

The results suggest that cock ileum would be the one of the good alternative in the tissue experimentation where we can save animals for other research purpose.

\section{ACKNOWLEDGMENTS}

Authors are thankful to department of pharmacology of PDEA's Seth Govind Raghunath Sable College of Pharmacy, Saswad for providing research facilities required for this work.

\section{REFERENCES}

[1]. Chand N, Eyre P. The pharmacology of anaphylaxis in the chicken intestine. Br. J. Pharmac. 1976; 57: 399-408.

[2]. Kulkarni SK. Editor. Handbook of Experimental pharmacology. $2^{\text {nd }}$ Edition. New Delhi: Vallabh prakshan; 1997: 25-27.

[3]. Ghosh MN. Editor. Fundamentals of Experimental Pharmacology. $2^{\text {nd }}$ Edition. Calcutta: Scientific book agency; 1984: 84-85.

[4]. Bodakhe SH, Dangi JS, Ram A, Namdeo KP, Bodakhe KS. Isolated cock ileum: a tool for pharmacology experiments. Indian J Pharm Educ Res. 2009; 43(2): 199-202. 